\title{
HISTÓRICO DA EXPANSÃO URBANA E OCORRÊNCIA DE INUNDAÇÕES NA CIDADE DE CUIABÁ-MT
}

\section{History of urban expansion and occurrence of flooding in the city of Cuiabá, Mato Grosso (Brazil)}

\author{
Frederico Carlos Martins de Menezes Filho
}

Universidade Federal de Viçosa, Rio Paranaíba, Minas Gerais, Brasil.

menezesfilho.frederico@gmail.com

Daiany Basilia Amaral daiany_27@hotmail.com

Artigo recebido em 22/04/2013 e aceito para publicação em 02/10/2013.

RESUMO: O presente trabalho analisou os documentos que registraram as inundações no município de Cuiabá no período de 1970 a 2010. As etapas de pesquisa abrangeram a mídia impressa/digital, defesa civil municipal e o acervo disposto na Biblioteca Central do município. O objetivo principal deste trabalho foi estabelecer a relação entre crescimento urbano e a incidência de inundações no município. Contabilizaram-se cinquenta e um eventos concentrados nos meses de dezembro a abril e uma média de 1,28 ocorrências por ano no período analisado. A expansão do perímetro urbano no início dos anos 1960 favoreceu a ocupação de forma desordenada do uso do solo e o incremento das inundações urbanas, seja pela intensa impermeabilização como também pela retificação e canalização dos córregos urbanos como o Córrego da Prainha e o Córrego do Barbado. As avaliações revelam que a urbanização da capital de Mato Grosso influenciou no aumento da frequência de inundações e os seus impactos repercutiram em prejuízos de natureza material e humana.

Palavras-chave: inundações urbanas; crescimento populacional; drenagem urbana.

ABSTRACT: This study examined documents that recorded floods in the municipality of Cuiabá between 1970 and 2010 . The steps of research encompassed printed and digital media, municipal civil defense and the collection of the Central Library of the municipality of Cuiabá. The main goal of this study was to establish a relationship between urban sprawl and incidence of floods in the municipality. Fifty-one flood events were recorded, concentrated in the months from December to April, with an average of 1.28 occurrences per year in the period analyzed. The expansion of the urban area in the early 60 's has favored the disordered occupation of land use and the increase of urban floods, either by the intense waterproofing as well as by channeling of urban streams, as observed in the Prainha and Barbado streams. The results revealed that the urbanization of the capital of Mato Grosso State has influenced in increasing the frequency of floods and their impacts have caused in losses of material and human nature.

Keywords: urban floods, population growth, urban drainage. 


\section{INTRODUÇÃO}

A partir da segunda metade do século XX, a intensa concentração populacional em áreas urbanas se tornou um fenômeno mundial.

Consoante dados do Centre for Reasearch on The Epidemiology of Disasters (EM-DAT, 2012) reportados no período 1900-2011 (Figura 1), visualiza-se no período supracitado a grande incidência das inundações e tormentas ocorridas seja por condições naturais ou oriundas de atividades humanas pelo desmatamento, degradação do solo, urbanização e drenagem urbana ineficiente (JAKUBICKA et al., 2010).

Segundo dados do último Censo Demográfico (IBGE, 2010), a população urbana brasileira atualmente corresponde a $84,3 \%$ da população total do país e uma pequena parte, ainda no campo, com o percentual de $15,64 \%$.

O centro-oeste brasileiro segue a mesma taxa, com Cuiabá, a capital do Estado de Mato Grosso agregando 98,1 \% da população em área urbana consoante o mesmo censo.
No Brasil, a concepção higienista que prevaleceu na década de 70 do século passado (SILVEIRA, 1998), fez da canalização e retificação dos córregos urbanos juntamente com a execução das galerias de águas pluviais, a única solução aos problemas urbanos de alagamentos e inundações. $\mathrm{O}$ intuito desta concepção foi transferir a jusante para o mais longe da população o volume gerado pelas águas das chuvas, sem a devida preocupação dos impactos causados ao ciclo hidrológico, seja pelo aumento dos picos das vazões, ou ainda, a diminuição da recarga das águas subterrâneas.

Os impactos da urbanização remetem não somente aos aspectos quantitativos mas também aos qualitativos por meio da poluição difusa, responsável pelo aporte de poluentes lavados da superfície durante os períodos chuvosos aos cursos d'água urbanos.

Neste panorama, percebe-se a necessidade de medidas mitigadoras sejam elas estruturais ou não, no objetivo único da reflexão sobre a atual ocupação adotada em nossas cidades a fim de dirimir sobre as soluções viáveis para um meio que já se encontra consolidado e intensamente antropizado.

Figura 1. Desastres reportados no período 1900-2011.

Números de desastres reportados 1900-2011

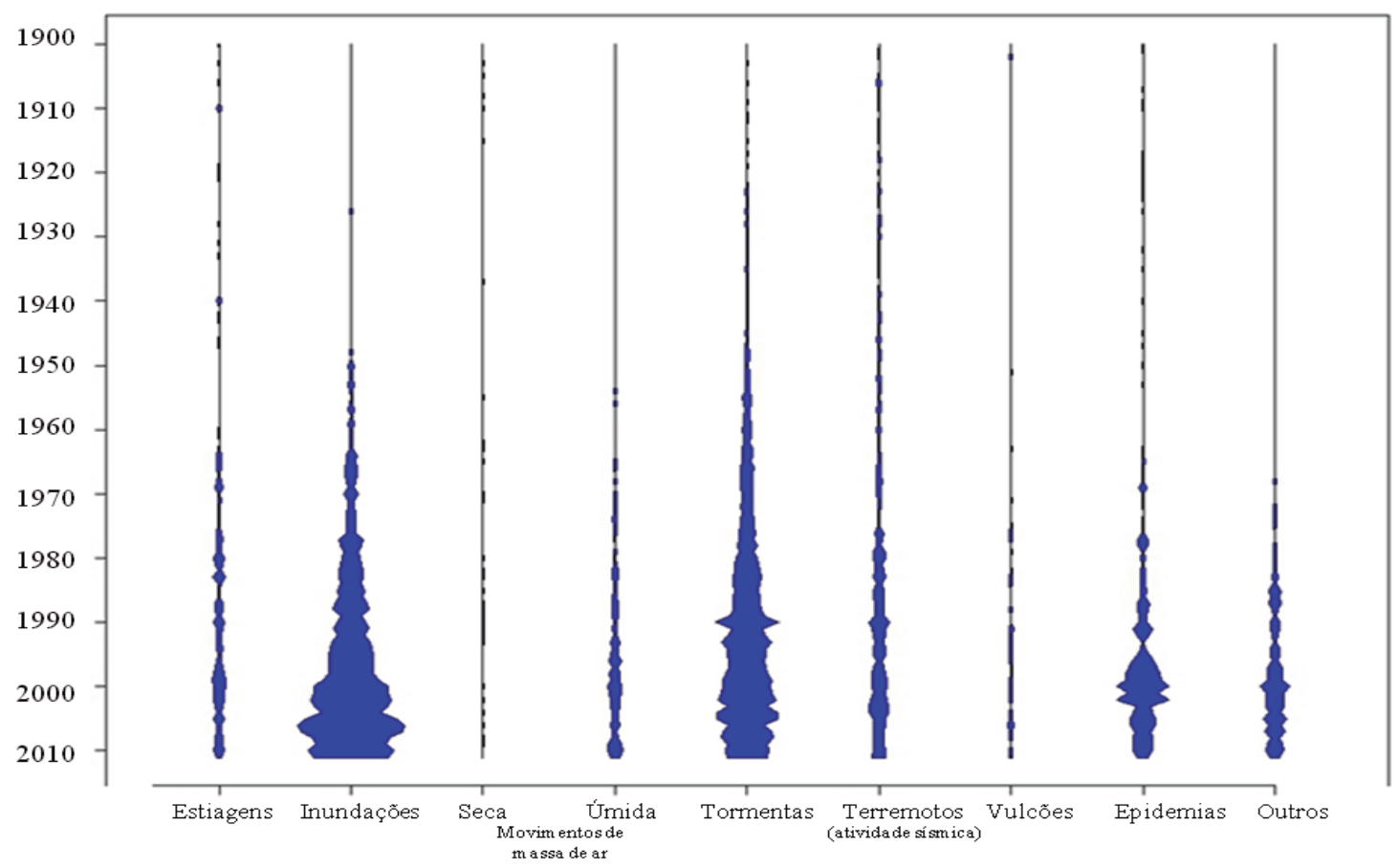

Fonte: EM-DAT - The OFDA/CRED International Disaster Database. Disponível em: http://www.emdat.be/database. 


\section{OBJETIVOS}

O presente trabalho teve como objetivo principal o levantamento histórico, baseado em dados da Defesa Civil, publicações em jornais, fotos da cidade e bibliografias acerca da incidência de inundações relacionadas com o processo de expansão urbana na capital mato-grossense.

A partir desta análise buscou-se levantar dados para apontar as direções às medidas mitigadoras necessárias.

Dentre os objetivos específicos citam-se:

- Resgatar e discutir o processo histórico de expansão urbana e sua relação com a incidência de inundações em corpos d'água sem dados históricos sistematizados, na cidade de Cuiabá-MT;

- Recuperar dados de suma importância que relacionem as ocorrências de inundações e alagamentos com a urbanização da bacia, por meio de pesquisas realizadas na defesa civil do município de Cuiabá, notícias de jornais da cidade, acervo da biblioteca Central e bibliografias;

- Dispor em banco de dados ocorrências de inundações, para futura utilidade pública, como benefícios para implantar medidas mitigadoras e para realização de novos projetos;

- Traçar soluções viáveis aos problemas enfrentados pela cidade no que tange principalmente à ocorrência de inundações.

\section{COLETA DE DADOS}

A busca de informações iniciou-se em junho de 2011. Em virtude da carência de arquivos relativos ao tema e da dispersão dos mesmos em diversos órgãos, fez-se necessário a sistematização para busca de tais fontes seguindo o fluxograma apresentado na Figura 2, com quatro etapas.

Figura 2. Fluxograma apresentando as quatro etapas realizadas no trabalho

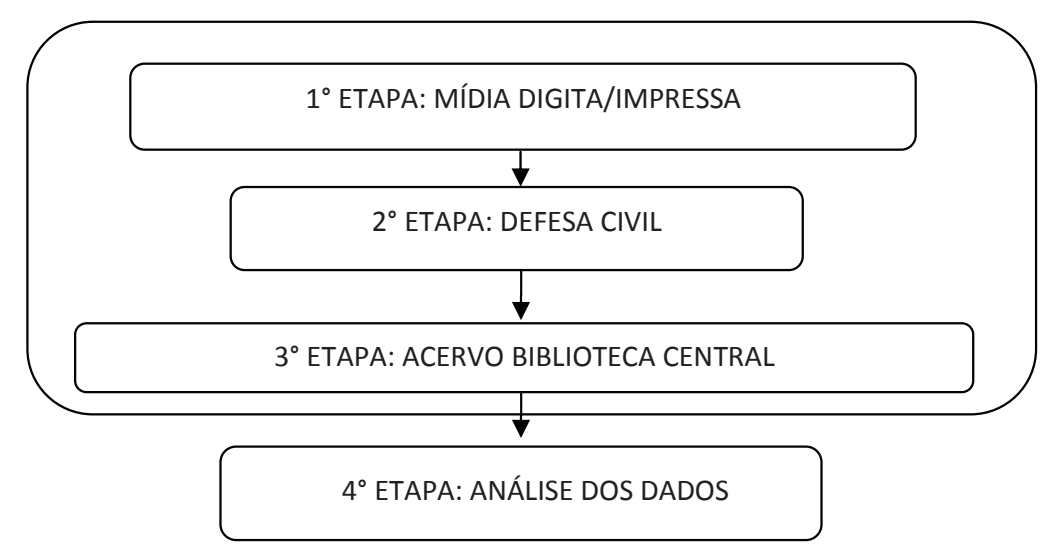

Org. dos autores.

Na primeira etapa (Figura 3) buscaram-se as informações nos três principais jornais da cidade: Diário de Cuiabá, A Gazeta e Folha do Estado, fundados respectivamente nos anos de 1969, 1990 e 1995. As informações compreenderam os temas correlatos ao tema: inundações, enchentes e alagamentos que ocorreram no município de Cuiabá compreendendo rios, córregos e ribeirões da cidade.
A coleta de dados procedeu primeiramente na busca pelo jornal digital e posteriormente na própria edição do jornal à procura de jornais impressos. Formou-se uma planilha de dados com as noticias relevantes, incluindo o ano do acontecimento, área inundada, danos causados, pessoas atingidas (Quadro 1). 
Quadro 1. Exemplo da parte dos dados das inundações ocorridas nos anos de 2009 e 2010

\begin{tabular}{|c|c|c|c|}
\hline Data da chuva & Área de abrangência & Danos causados & Pessoas atingidas \\
\hline $15 / 04 / 2009$ & $\begin{array}{c}\text { Bairros Jardim do Aeroporto, Jardim dos } \\
\text { Estados, Centro de Várzea Grande e Ipase. }\end{array}$ & Casas inundadas & Não Informado \\
\hline $28 / 05 / 2009$ & $\begin{array}{c}\text { Av. Fernando Correia da Costa, Tijucal, Bos- } \\
\text { que da Saúde II, Dom Aquino, Av. CPA e Av. } \\
\text { Miguel Sutil }\end{array}$ & $\begin{array}{c}\text { Alagamento de } \\
\text { avenidas, ruas e } \\
\text { residências }\end{array}$ & Não informado \\
\hline $16 / 02 / 2010$ & $\begin{array}{c}\text { Peixoto de Azevedo, Cáceres, Cuiabá, Santo } \\
\text { Antônio de Leverger, Várzea Grande, Como- } \\
\text { doro, Tangará da Serra e Barra dos Bugres. }\end{array}$ & $\begin{array}{c}\text { Pessoas desabri- } \\
\text { gadas, isoladas, } \\
\text { pontes quebradas }\end{array}$ & 40 famílias \\
\hline $5 / 12 / 2010$ & $\begin{array}{c}\text { Consil e Boa Esperança.Avenida Historiador } \\
\text { Rubens de Mendonça (Avenida do CPA), } \\
\text { Avenida Miguel Sutil e região do Coxipó. }\end{array}$ & $\begin{array}{c}\text { Quedas de muro, } \\
\text { letreiros, piscinas } \\
\text { e até bombas } \\
\text { de combustível, } \\
\text { falta de energia. }\end{array}$ & Não informado \\
\hline
\end{tabular}

Org. dos autores.

O período de análise compreendeu o intervalo de 1970 a 2010, dado que o primeiro jornal impresso instalado no município deu-se no ano de 1969.

Figura 3. Fluxograma da $1^{\circ}$ Etapa: coleta de dados dos jornais do município de Cuiabá.

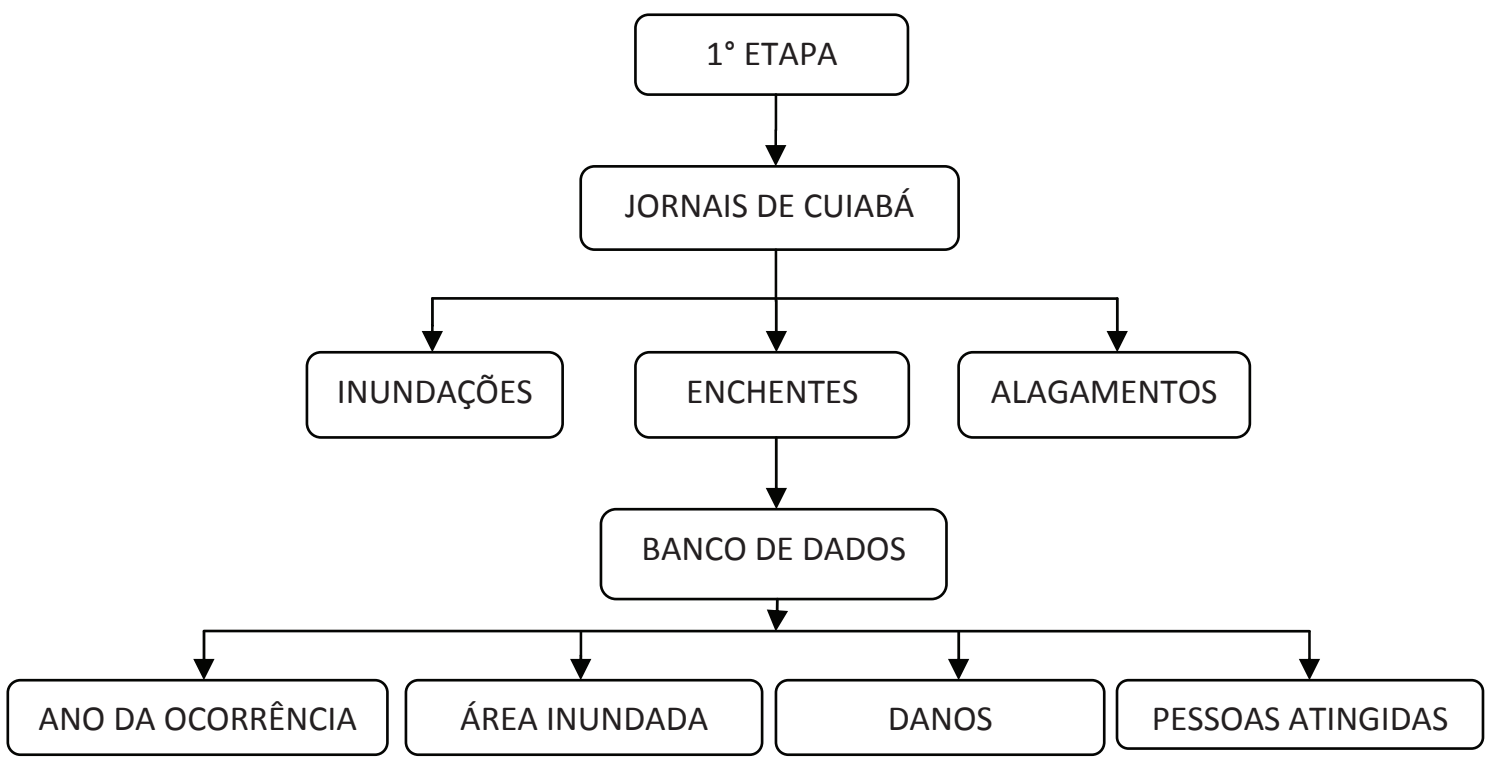

Org. dos autores. 
A segunda etapa (Figura 4) correspondeu à visita a Defesa Civil do município com o fornecimento de arquivos, fotos e vídeos das inundações que ocorreram, o mapa de risco da cidade contendo todos os corpos d'água e as delimitações das Áreas de Preservação Permanente (APP), permitindo a identificação dos córregos que se encontram canalizados.

A Defesa Civil forneceu arquivos acerca dos dias que o rio Cuiabá alcançou maiores cotas correspondentes às precipitações no período 1960 - 2010. Os dados foram coletados no Posto da Régua - Departamento Nacional de Águas e Energia Elétrica (DNAEE), localizado no rio Cuiabá que possui Cota de Alerta 8,50m; Cota de Emergência 9,50m e Cota de Calamidade $11,00 \mathrm{~m}$.

Com os dados dos dias que o rio Cuiabá adquiriu a maior cota foi possível localizar as possíveis inundações que ocorreram na cidade. Estipulou-se um padrão de altura da régua que segundo a Coordenadoria da Defesa Civil municipal, provavelmente ocorreria a inundação, sendo este o valor de 5,00 metros.

Baseado nesta informação efetuou-se a busca nos jornais impressos nos dias que a cota do Rio Cuiabá atingira a marca de 5,00 m. Em seguida recorreramse às mesmas datas nos jornais a fim de confirmar a ocorrência ou não da inundação. Do mesmo modo, a busca se deu para os dias próximos ao evento registrado. Quando confirmado, a reportagem era fotografada e arquivada e seus dados relevantes extraídos.

A terceira etapa teve como objetivo a junção de fotos adquiridas no acervo da Biblioteca Central de Cuiabá, permitindo demonstrar as transformações territoriais ocorridas no município desde sua ocupação urbana até a atualidade. Algumas destas fotos tornam possíveis as comparações da mesma área sendo ocupada em diferentes épocas.

Figura 4. Fluxograma da $2^{\circ}$ Etapa: coleta de dados na Defesa Civil do Município de Cuiabá.

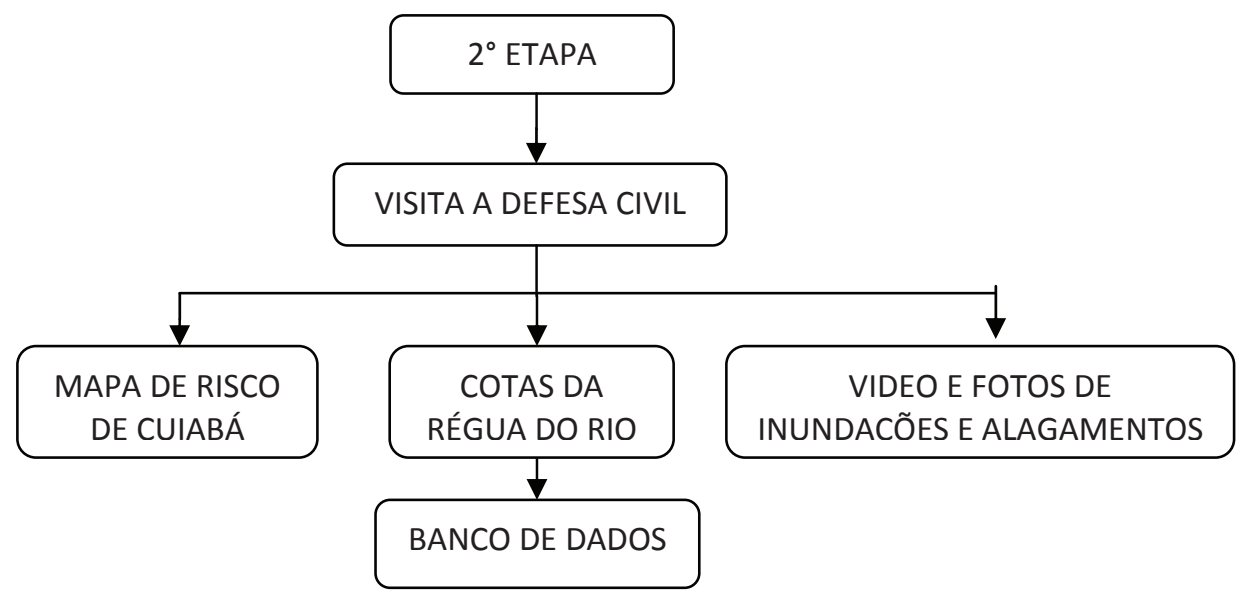

Org. dos autores.

EXPANSÃO URBANA E OCUPAÇÃO DE FUNDOS DE VALE EM CUIABÁ

A evolução urbana no município de Cuiabá se desenvolveu às margens do rio Cuiabá com o crescimento ao longo do córrego da Prainha que hoje se encontra com seu leito canalizado em $75 \%$ (CUIABÁ, 2008).

A ocupação urbana nesta época era limitada pelos córregos que se encontravam próximos deste, dentre eles: o Mané Pinto, Engole Cobra e Gambá, possuindo ainda como limite o Ribeirão do Lipa. A urbanização nas margens do rio Cuiabá ocorreu nos séculos XVIII e XIX, sendo que a primeira delimitação do perímetro urbano foi reconhecida legalmente no Ato $n^{\circ} 176$ de 25/07/1938 (CUIABÁ, 2008).

Já no século XX, no período de 1901 a 1960 houve a ocupação nas margens dos córregos Gambá, Quarta-Feira, Barbado, Fundo, São Gonçalo, Figueirinha, Imbauval e do rio Coxipó. Dessa forma a população às margens do Cuiabá continuava a crescer no sentido jusante-montante consoante aponta Tucci 
(2004) ao descrever a tendência do processo de urbanização em bacias hidrográficas.

Doravante, a análise revelou que no período posterior compreendido entre 1961 e 1990 ocorreu a maior ocupação urbana do município atingindo diferentes pontos da capital, sempre nos fundos de vale dos córregos já povoados e alguns outros: Santa Isabel, Moinho, Bangue, Gumitá, Cajú, Vassoral, Três Barras, Tijucal, Para Tudo, Fortaleza, São José do Sapateiro, Aricá, Lavrinha, Caite e os Ribeirões dos Peixes e o Baú, além de um maior numero de pessoas habitando na extensão do rio Coxipó.

Segundo dados da Prefeitura Municipal de Cuia- bá, até a década de 60 do século XX o município possuía um crescimento populacional estabilizado às margens do córrego da Prainha, sendo de 57.860 mil habitantes.

Com os incentivos fiscais e créditos fornecidos pela SUDAM (Superintendência do Desenvolvimento da Amazônia) na década de 60, grandes empresas agropecuárias se instalaram no estado e ocorreu a ocupação do norte mato-grossense, tornando Cuiabá um pólo de apoio à ocupação da Amazônia meridional brasileira (CUIABÁ, 2010). Com isto a população duplicou para 100.865 mil habitantes no ano de 1970, atingindo a marca de 212.984 mil em 1980, devido as migrações (Figura 5).

Figura 5. Taxa de urbanização $\left(\mathrm{km}^{2} / \mathrm{ano}\right)$ no município de Cuiabá.

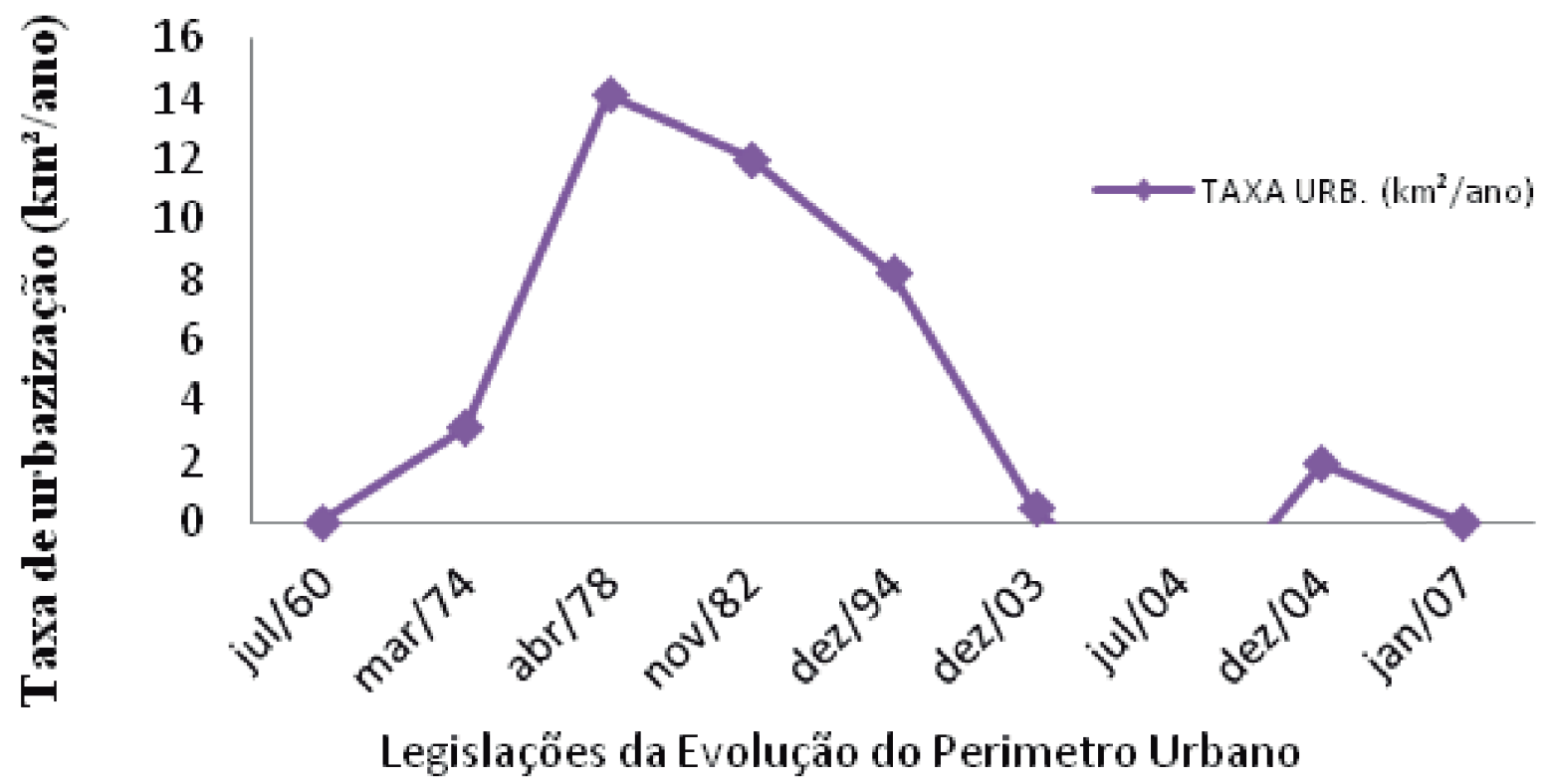

Fonte: Plano Diretor de 2007 (CUIABÁ, 2010). Org. dos autores.

Paralelamente a nível nacional verificou-se no período de 1996 a 1986 a inversão campo-cidade, com o intenso êxodo rural e uma demanda jamais vista sobre a infraestrutura urbana destacando-se elementos do saneamento ambiental, bem como saúde, transporte e moradia (Figura 6). 
Figura 6. Crescimento populacional brasileiro no período 1950-2010.

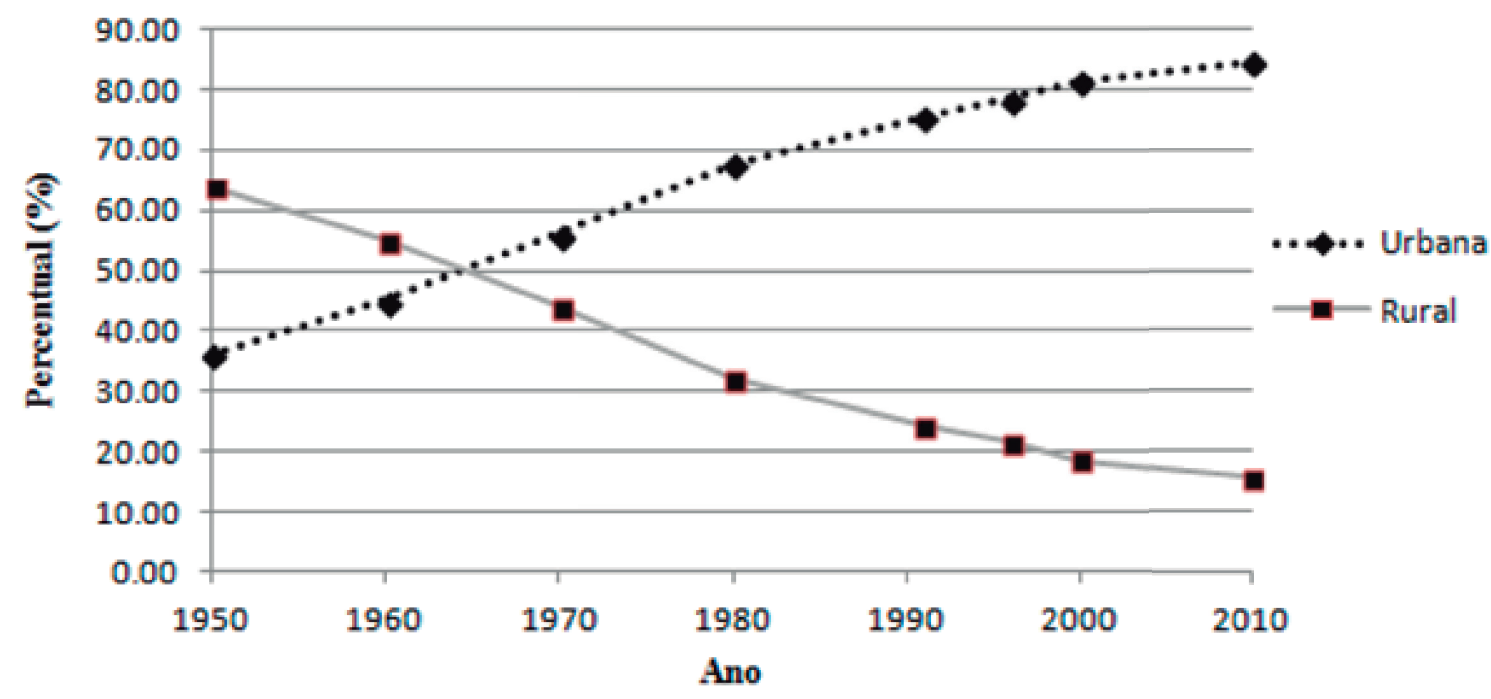

Fonte: IBGE (2011). Org. dos autores.

Assim, a área urbana existente não suportava toda população, por isso o limite do perímetro urbano foi ampliado em três etapas nos anos de 1974, 1978 e 1982. Justamente em 1979 com alta urbanização realizou-se a cobertura do córrego da Prainha que já se encontrava canalizado desde 1962 (CUIABÁ, 2010). As justificativas para esta ação compreenderam desde o curso d'água ter se transformado em esgoto a céu aberto, a necessidade de viabilizar a implantação de uma via, a implantação dos interceptores de esgotos, facilidade da manutenção do córrego e o aumento da velocidade de escoamento.

De fato a concepção higienista ainda prevalecente, alterou este córrego retificando e canalizando em detrimento das soluções viárias de transporte da capital, bem como, da ocultação do mesmo, sendo encarado como um empecilho, assim como a nível nacional àquela época, ao desenvolvimento urbano. Cabe ressaltar ainda, a existência do sistema misto ou combinado para coleta do esgoto doméstico e das águas pluviais desaguando nos córregos urbanos, dentre eles o córrego do Barbado, outro córrego canalizado.

Já em 1990, segundo o censo de 1991 (IBGE, 2011) a população cuiabana superava 400 mil habitantes. Assim, no período de 1960 a 1991, houve um aumento populacional de 596\%, sendo necessária a implantação de núcleos habitacionais. Como a maioria fora construída para além do perímetro urbano foi necessária sua incorporação com a legislação de 1994, permitindo assim os proprietários regularizarem seus imóveis conforme a lei urbana vigente.

O Banco Nacional de Habitação (BNH) era o responsável por financiar as moradias em Mato Grosso no período de 1966 a 1986. Devido ao alto crescimento populacional, foi o responsável por grande parte da construção de habitações para a população. Com sua extinção, foi a vez da COHAB-MT (Companhia de Habitação do Estado de Mato Grosso) ser a responsável por construir núcleos habitacionais. Com 30 anos de funcionamento se extinguiu em 1996, devido à falta de recursos públicos federais, aumentando assim as ocupações urbanas em áreas sem infraestrutura, como: áreas de preservação permanente, nascentes, córregos e outros (CUIABÁ, 2010).

Em 2003 ampliou-se novamente o perímetro urbano cujo objetivo era incluir o Condomínio Núcleo Habitacional Sucuri (localizado ao norte do município) para o assentamento de moradores residentes em áreas de risco de inundação. Entretanto, por engano a ampliação ocorreu na via de acesso ao Distrito da Guia, sendo em julho de 2004, a lei revogada e a área incorporada à região do Condomínio Núcleo Habitacional Sucuri. Deste modo, pela correção da área incorporada ser inferior a área antes determinada gerou uma taxa negativa da urbanização como se verifica na Figura 5. 
Em dezembro de 2004 ocorreu novamente a ampliação do perímetro urbano fato ocorrido sem nenhum embasamento técnico (CUIABÁ, 2008). No ano de 2007 foi sancionada a Lei ${ }^{\circ} 150$ pelo prefeito da ocasião, proibindo a ampliação do perímetro urbano pelo período de 10 anos, exceto em situação de calamidade pública (CUIABÁ, 2008).

\section{ANÁLISE DOS DADOS DE NOTÍCIAS DE JORNAL}

A Figura 7 indica que as ocorrências variaram de 1 a 4 eventos nos anos onde foram encontrados registros de inundações ou alagamentos $(1972,1974$,
1975, 1976, 1977, 1978, 1979, 1980, 1981, 1982, 1983, 1985, 1987, 1988, 1989, 1991, 1992, 1993, 1994, 1995, 1997, 1998, 2001, 2002, 2003, 2004, 2006, 2007, 2009, 2010). Para o ano de 1973 não detectou-se nenhum arquivo para análise nas fontes pesquisadas.

Consoante o jornal Diário de Cuiabá (1972) as maiores enchentes que o município sofrera foram registradas nos anos de 1865, 1905, 1941 e 1957, sustentando a análise de que a cidade de Cuiabá desde então já era susceptível a inundação, fato que não foi tido como relevante no início da ocupação urbana às margens do rio Cuiabá e do córrego da Prainha.

Figura 7. Número de ocorrência de inundações na cidade de Cuiabá no decorrer de 40 anos.

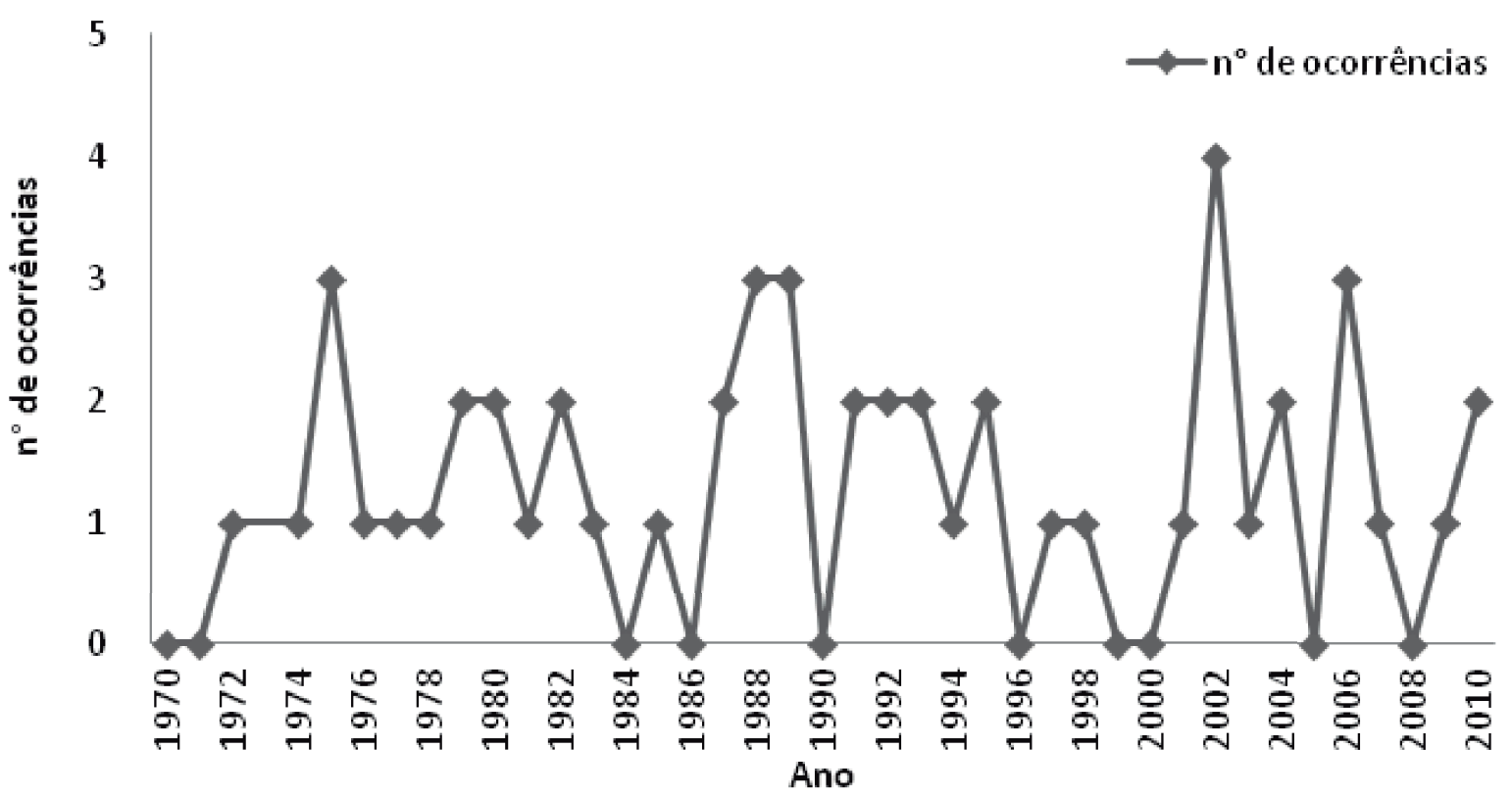

Org. dos autores.

\section{RELAÇÕES ENTRE URBANIZAÇÃO, OCOR- RÊNCIA DE INUNDAÇÕES E ALAGAMENTOS}

Os dados obtidos sobre as ocorrências de inundações e alagamentos no município de Cuiabá no período de 1970 a 2010 juntamente com a evolução populacional, revelam que o maior número de ocorrências de inundações e alagamentos ocorreu justamente quando a população teve seu maior crescimento e como visto anteriormente, no período 1960-1991 que evidenciou alta urbanização (Figura 8).

Na década de 90 não houve tantas ocorrências, mas ocorreu umas das maiores inundações, a de 1995 que trouxe grandes prejuízos a população. 
Figura 8. Relação entre, evolução populacional e ocorrência de inundações e alagamentos em Cuiabá.

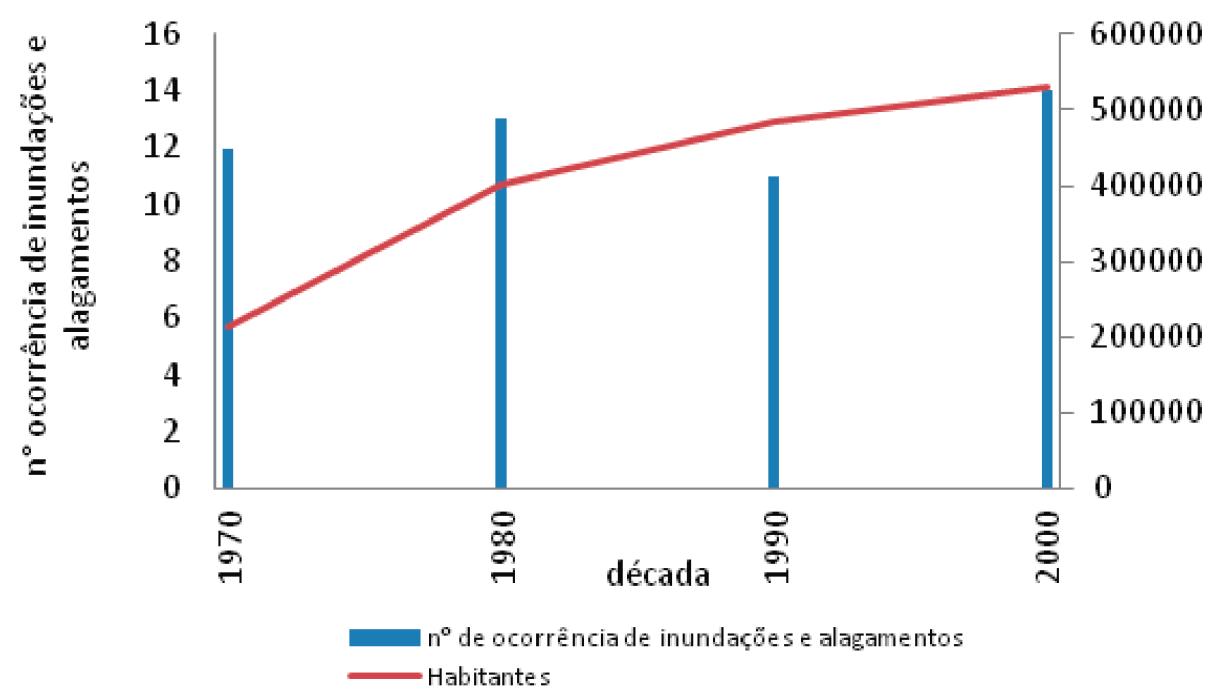

Fonte: IBGE, 2011. Dados levantados pelos autores. Org. dos autores.

\section{ANOS DE OCORRENCIA DAS MAIORES INUNDAÇÕES NA CIDADE DE CUIABÁ}

De todos os anos pesquisados nos jornais sobre ocorrência de inundações e alagamentos, as datas que causaram maiores danos à população de Cuiabá foram 1942, 1974, 1995 e 2001. Como não há arquivos encontrados para o ano de 1942, esta não foi incluída na análise.
Com base nos dados da defesa civil por meio da leitura da régua do rio Cuiabá é possível visualizar as cheias do rio em cada ano supracitado (Figura 9), com destaque para o ano de 1974 quando a cota atingiu nos meses de janeiro, fevereiro e março, respectivamente os valores de 7,5m; 4,7m e 10,9m, e para o ano de 1995 onde a cota marcou nos meses de janeiro, fevereiro e março os valores de 9,9m; 10,6 e 4,5m.

Figura 9. Anos de ocorrência das maiores inundações na cidade de Cuiabá.

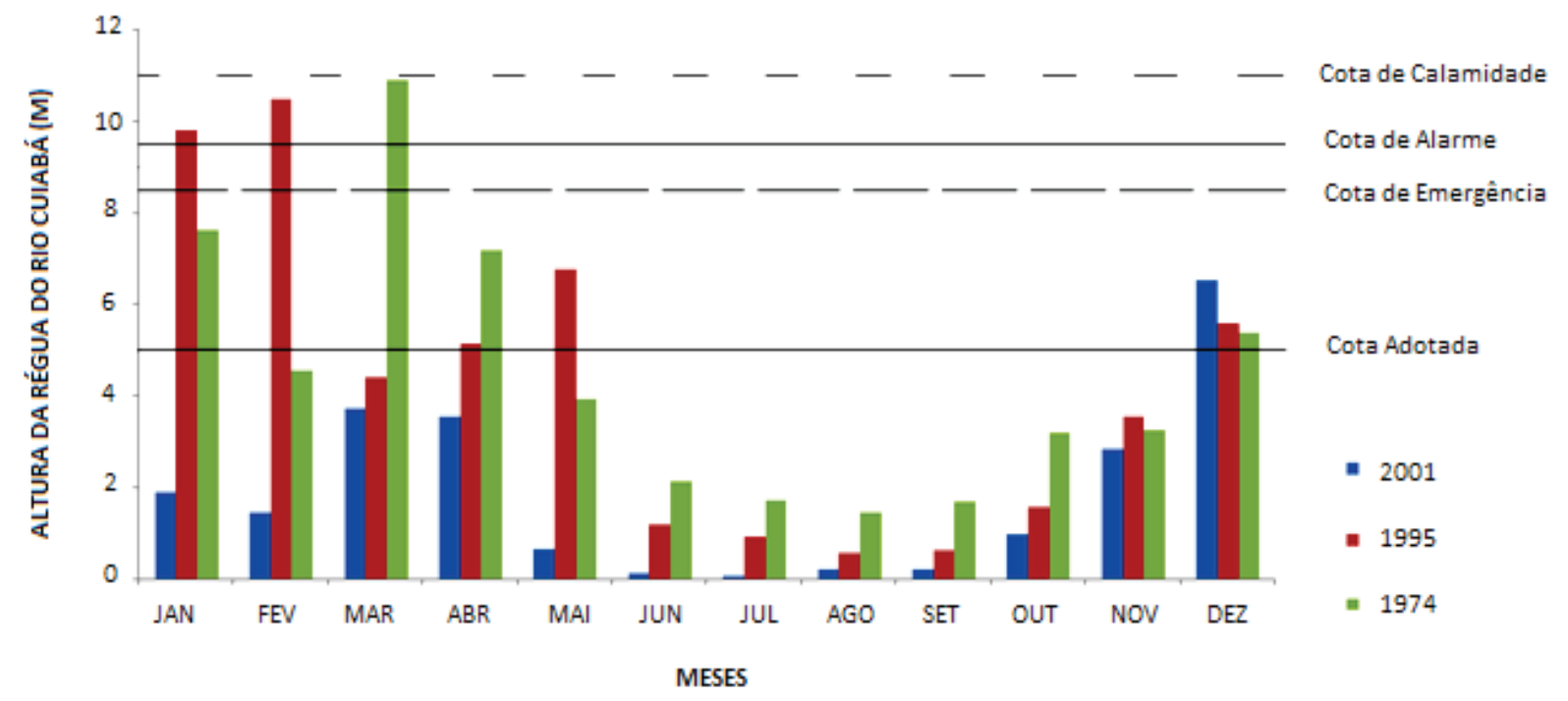

Fonte: Defesa Civil de Cuiabá. Org. dos autores. 


\section{EVOLUÇÃO HISTÓRICA DAS INUNDAÇÕES} E ALAGAMENTOS

Utilizando as imagens fornecidas pelo acervo da Biblioteca Central de Cuiabá foi possível extrair informações relevantes para o estudo da história das inundações e alagamentos tanto do rio Cuiabá quanto dos córregos.

Cuiabá se desenvolveu as margens de rios, ribeirões e córregos, e esse crescimento sem planejamento trouxe prejuízos à população e se propagam até os dias atuais. Nas fotos é possível corroborar esta afirmativa, observando-se o grande número de residências que se aglomeraram em zonas que deveriam ser preservadas como matas ciliares impedindo a erosão e o assoreamento.

A Figura 10 (a) apresenta a Av. Tenente Coronel Duarte, conhecida como Prainha na década de
1970. Comparando com a (b) é possível observar que com o crescimento populacional a paisagem urbana se tornou preponderante com grande ocupação a montante do Córrego Prainha, intensificando os impactos da urbanização sobre o corpo d'água com sua retificação e canalização por volta de 1962, sendo que em 1979 realizaram sua cobertura, como se observa.

Em imagem atual (Figuras (c) e (d)), observa-se a canalização inicial à margem direita do trecho "enterrado" onde hoje além do processo de erosão das margens, visualiza-se a ausência de limpeza pública e o total esquecimento por parte dos órgãos responsáveis. Há também a contribuição dos esgotos domésticos com ligações clandestinas pela ausência do sistema coletor de esgotos neste ponto da cidade, com a presença de material putrescível nas águas conduzidas.

Figura 10. (a) Vista da avenida Prainha, no cruzamento com a avenida Isaque Póvoas e arredores, na década de 1970. À esquerda, a Igreja de Nossa Senhora do Auxiliadora. Ao fundo, a torre da Igreja de São Gonçalo, no bairro do Porto; (b) Vista atual com o mesmo enquadramento. (c) Córrego da Prainha Canalizado. (d)

Matéria orgânica por ligação clandestina de esgoto no Córrego da Prainha.

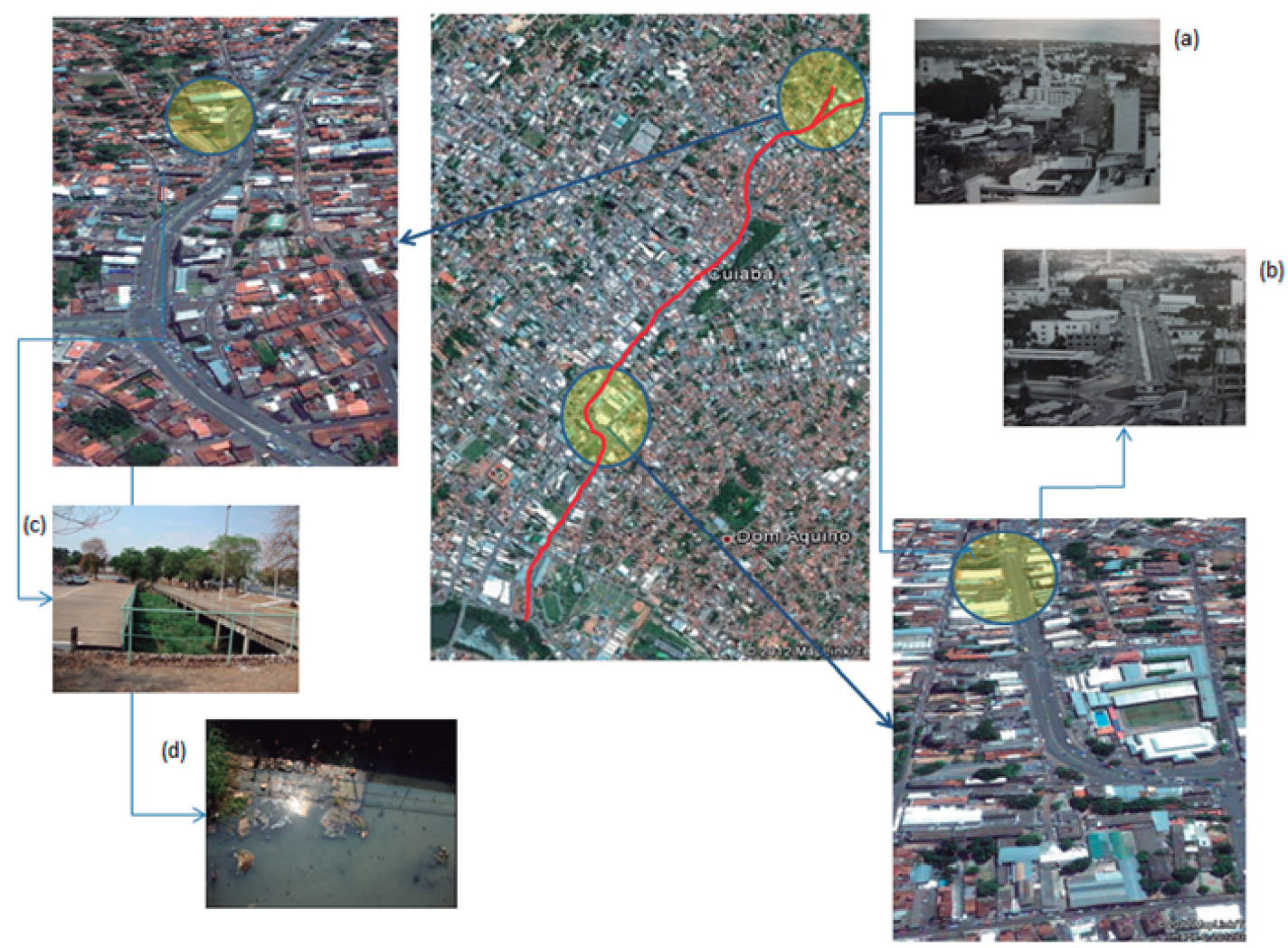

Fonte: Adaptado de Siqueira (2008) e Menezes Filho (2011). Elaboração dos autores. 


\section{CONCLUSÕES E RECOMENDAÇÕES}

No início da urbanização de Cuiabá-MT, a população se instalou nas várzeas de inundação que constituem o leito maior do Rio Cuiabá, bem como em locais como fundos de vales dos rios próximos àquele principal e ribeirões e córregos como Prainha, Barbado, Gambá, Mané Pinto e outros da cidade, tornando-se assim sujeita assim a eventos inesperados e sofrendo as consequências como perdas materiais e humanas.

Além das ocupações irregulares, a ocupação legal dada pela expansão do perímetro urbano nos anos 1970 até o período atual, favoreceu a impermeabilização do solo gerando pressões sobre os serviços de infraestrutura, incluindo a drenagem urbana e todos os seus impactos sobre o escoamento superficial.

Outro fator contundente para atenuação dos problemas verificados na área urbana relacionados às inundações são os resíduos sólidos lançados na cidade, que obstruem as redes de drenagem como as bocas de lobos e córregos. Tanto a ausência de limpeza pública quanto a falta de conscientização da população agravam esta situação.

Indica-se como recomendações complementares:

- A elaboração de um Plano Diretor de Drenagem Urbana, como relatado no Plano Diretor de Desenvolvimento Estratégico (CUIABÁ, 2008) e ainda não implementado, a fim de subsidiar medidas para atenuar a geração de áreas impermeáveis e resgate das condições de pré-ocupação com técnicas compensatórias: bacias de detenção, pavimentos permeáveis; trincheiras de infiltração, dentre outras;

- A recuperação ou a revitalização dos córregos urbanos, tornando esses ambientes integrados à sociedade e desvinculando a imagem puramente de local destinado a esgotos e resíduos sólidos;

- Somente a construção de núcleos habitacionais para a população retirada das zonas de riscos de inundação não é o suficiente. É preciso o desenvolvimento de projetos que transformem a área desocupada em área de utilidade pública, como parques lineares, ciclovias; sobretudo pensando no uso coletivo;

- Contemplação de medidas não estruturais, peças fundamentais neste processo, abrangendo campanhas educativas por meio de palestras, divulgação em meios de comunicação em massa sobre o descarte inadequado de resíduos em locais impróprios, bem como da ligação clandestina de esgotos ao corpo d'água mais próximo;

- Planejamento sistemático de limpeza pública, visto que a limpeza não é regular e a mesma ocorre muitas vezes após o início das chuvas.

\section{AGRADECIMENTOS}

Os autores agradecem a Defesa Civil (Cuiabá) que disponibilizou acesso aos arquivos e aos colaboradores dos Jornais A Gazeta, Diário de Cuiabá e Folha do Estado.

\section{REFERÊNCIAS}

CUIABÁ. Prefeitura.. Plano Diretor de Desenvolvimento Estratégico de Cuiabá. Instituto de Planejamento e Desenvolvimento Urbano-IPDU (org. por Adriana Bussiki Santos). Cuiabá: Entrelinhas, 2008.

CUIABÁ. Prefeitura. Perfil socioeconômico de Cuia$b a ́$. Volume IV. Instituto de Planejamento e Desenvolvimento Urbano-IPDU. (Org. por Adriana Bussiki Santos). Cuiabá: Central de Texto, 2010.

DIÁRIO DE CUIABÁ. Rio Cuiabá já provocou 4 enchentes- Este ano será a quinta? Diário de Cuiabá. Cuiabá, 20 de fevevereiro de 1972.

EM-DAT. EM-DAT: The OFDA/CRED International Disaster Database. Université Catholique de Louvain - Brussels - Belgium. Disponível em: www.em-dat. net. Acesso em: 24 jul. 2012. 
IBGE. Instituto Brasileiro de Geografia e Estatística. Sistema IBGE de Recuperação Automática. Disponível em: http://www.sidra.ibge.gov.br/. Acesso em: 18 fev.2011

JAKUBICKA, T; VOS, F; PHALKEY, R; MARX, M. GUHA-SAPIR, D. Health impacts of floods in Europe - Data gaps and information needs from a spatial perspective. MICRODIS Report. Centre for Research on The Epidemiology of Disasters-CRED - School of Public Health, Catholic University of Louvain. November, 2010.

MENEZES FILHO, F. C. M. Córrego da Prainha, Cuiabá- MT. Imagens Exclusivas. Recursos Hidricos... Desafios no século XXI. Disponível em: $<$ http:// menezesfilho.blogspot.com>. Acesso em: 29 de Novembro de 2011.

SILVEIRA, A. L. L da. Hidrologia urbana no Brasil. In: Braga, B. P. F; Tucci, C. E. M; Tozzi, M. (org.) Drenagem urbana: gerenciamento, simulação, controle. Porto Alegre: Editora da UFRGS/ABRH, 1998. p.8-25.

SIQUEIRA, E. M. Cuiabá: de vila a metrópole nascente. Cuiabá: Entrelinhas, 2006.

TUCCI, C. E. M. (Org.). Hidrologia ciência e aplicação. 3 ed. Porto Alegre: Editora da UFRGS/ABRH, 2004. 943p.

TUCCI, C. E. M. Inundações urbanas. Porto Alegre: ABRH/RHAMA, 2007. 393 p. 